\title{
SISTEMA DE PENSIONES Y PROFUNDIDAD FINANCIERA: EVIDENCIA EMPÍRICA DE COINTEGRACIÓN PARA EL CASO BOLIVIANO
}

\section{Pamela Córdova Olivera}

\section{RESUMEN}

El objetivo de este artículo es evaluar empíricamente la naturaleza de la relación entre el Sistema de Pensiones basado en cuentas de capitalización individual y la Profundidad Financiera en Bolivia. Para este propósito, se utilizan el contraste de cointegración de Engle- Granger y de Johansen dentro de un marco de corrección de errores, esto con el fin de poder confirmar la existencia de una relación estable de largo plazo entre las variables. En general, los resultados apoyan la opinión de que, en efecto, el Sistema de Pensiones es un factor causal de Profundidad Financiera y que tiene efectos duraderos a largo plazo. Por lo tanto, las políticas gubernamentales diseñadas para fortalecer el Sistema de Pensiones deben ser persistentes y sostenibles con el fin de promover, paralelamente al desarrollo social e inclusivo del Sistema de Seguridad Social, el desarrollo de los Mercados de Capitales. Para el análisis se plantea un modelo econométrico de Profundidad Financiera con dos especificaciones alternativas: i) la primera excluye títulos públicos y ii) la segunda incluye títulos públicos.

Palabras Clave: Profundidad Financiera, Sistema de Pensiones, Cointegración.. 